\title{
The Relationship Among Fasting Blood Glucose, Lipid Panel, and Global Scoring of Myocardial Perfusion Imaging
}

\section{(1) Emine Acar1,2}

1İzmir Katip Çelebi University, Atatürk Training and Research Hospital, Clinic of Nuclear Medicine, İzmir, Turkey

${ }^{2}$ Dokuz Eylül University, Institute of Health Sciences, Department of Translational Oncology, İzmir, Turkey

\begin{abstract}
Objectives: This study aimed to evaluate the impact of fasting blood glucose and lipid panel values on the scores in myocardial perfusion scintigraphy (MPS) and the percentage of perfusion defects.

Materials and Methods: Medical data of 1120 consecutive patients were reviewed. The fasting blood glucose and lipid panel values within \pm 30 days from MPS imaging were considered. A total of 274 (24\%) patients (125 female, 149 male) were included in the study. Summed stress score (SSS), summed rest score, summed difference score (SDS), stress total perfusion defect (TPD), rest TPD, and difference TPD values were obtained by using a semi-quantitative (17 segment model, 5-point scoring)

method. The ejection fraction (EF) was measured via the MPS images that synchronized with an electrocardiogram. Fasting blood glucose, lipid profile, ejection fraction, gender, and the presence of coronary artery disease were compared to MPS scores and TPD percentages by using the t-test. A logistic regression test was used to detect the parameters that might cause abnormal SSS and SDS scores. Results: Perfusion defects (SSS $>3$ ) were observed in $196(72 \%)$ patients. In $172(63 \%)$ of these patients, there was a reversible perfusion defect ( $\mathrm{SDS}>2)$. During MPS imaging, decreased HDL $(<40 \mathrm{mg} / \mathrm{dL})$ and increased fasting blood glucose $(>125 \mathrm{mg} / \mathrm{dL})$ levels in all patients, elevated triglyceride $(>200 \mathrm{mg} / \mathrm{dL})$ values in the coronary
\end{abstract}

Address for Correspondence: Emine Acar, İzmir Katip Çelebi University, Atatürk Training and Research Hospital, Clinic of Nuclear Medicine, İzmir, Turkey and Dokuz Eylül University, Institute of Health Sciences, Department of Oncology, İzmir, Turkey

Phone: +90 5354638081 e-mail: emineacar87@gmail.com ORCID: orcid.org/0000-0002-6861-8814

Received: 04.07.2019 Accepted: 15.08.2019

Cite this article as: Acar E. The Relationship Among Fasting Blood Glucose, Lipid Panel, and Global Scoring of Myocardial

Perfusion Imaging.

EJCM 2019;7(3):133-141.

DOI: 10.32596/ejcm.galenos.2019.07.038

${ }^{\circ}$ Copyright 2019 by Heart and Health Foundation of Turkey (TÜSAV) / E Journal of Cardiovascular Medicine published by Galenos Publishing House. 


\begin{abstract}
artery disease $(\mathrm{CAD})+$ group, high total cholesterol $(>200$ $\mathrm{mg} / \mathrm{dL})$ and decreased HDL $(<40 \mathrm{mg} / \mathrm{dL})$ levels in the non-CAD group were the factors that were found to have statistically significant association with higher global scores. Independently from the fasting blood glucose and lipid profile, impaired EF values $(<50 \%)$ and male gender led to significantly higher global scores. While EF value and male gender were determined as independent factors
\end{abstract}

\section{Introduction}

Single-photon emission computed tomography (SPECT) and imaging of myocardial perfusion scintigraphy (MPS) with radiotracers are widely used in order to establish the diagnosis, to assess the risk and treatment management, and to evaluate treatment response of coronary artery disease ${ }^{(1)}$. In the evaluation of the MPS, visual and automatically calculated 17 segments, 5-points scoring evaluation methods are frequently utilized. Thus, the prevalence and severity of perfusion anomaly can be indicated by a single semi-quantitative measurement ${ }^{(2)}$. Basically, in MPS, two different images identified as stress and rest are evaluated. In stress images, the total of scores in all 17 segments are entitled as summed stress score (SSS), similarly, the overall score in rest images are entitled as summed rest score (SRS). The difference between these scores constitutes the summed difference score $(\mathrm{SDS})^{(3)}$. Furthermore, total perfusion defect percentage (stress TPD) of the left ventricular mass in the stress images and total perfusion defect percentage (rest TPD) of the left ventricular mass in rest images can be obtained from the program. The difference between these two values constitutes the difference TPD. SDS and difference TPD are in association with reversible defect. In case of the difference TPD $\geq 10$, an emergent coronary angiography is suggested for revascularization ${ }^{(4,5)}$.

Diabetes is a well-known risk factor for coronary artery disease for over decades ${ }^{(6)}$. It is known that microvascular for abnormal SSS, triglyceride and female gender were found to be in association with abnormal SDS.

Conclusion: This study emphasises that fasting blood glucose, lipid profile, gender, and EF values may be used as a beneficial tool to predict the MPS global scores and perfusion defect rates.

Keywords: Myocardial perfusion scintigraphy, global scoring, SSS, SDS, TPD

and macrovascular dysfunction gradually develop in patients with high blood glucose levels ${ }^{(7)}$. On the other hand, elevated cholesterol levels cause endothelial dysfunction hence lead to ischemic heart disease ${ }^{(8)}$. Dysfunction areas in vessels that occur secondary to impaired glucose and lipid parameters can be detected via MPS images.

This study aimed to determine the effects of fasting blood glucose and lipid panel [total cholesterol, triglyceride, high-density lipoprotein (HDL), lowdensity lipoprotein (LDL)] values on the perfusion defect percentages and scoring systems in myocardial perfusion scintigraphy.

\section{Materials and Methods}

The hospital records of overall 1120 consecutive enrollees who underwent myocardial perfusion scintigraphy with the suspect/diagnosis of coronary artery disease between July 2018 and April 2019 were retrospectively reviewed. Six hundred and ninety nine patients who had no biochemical tests in 30 days before or after the MPS and 140 patients without rest images were excluded from the study. The process of six patients could not be performed optimally due to gastrointestinal system activity. In addition to these, one patient was excluded for the reason that electrogram syncranized (GATED) image was not possible to obtain due to arrhythmia. Consequently, 274 patients were included. This study was approved by the Local Ethical Committee. 
All patients who underwent both stress and rest myocardial perfusion scintigraphy and had fasting blood glucose and lipid profile (total cholesterol, triglyceride, HDL, LDL) within \pm 30 days from the MPS date were included in the study.

On the other hand, the patients who had no fasting blood glucose and lipid profile analyses within the first 30 days before or after the MPS in the hospital database were excluded. Besides, the patients without resting MPS or GATED imaging and the patients with failed optimal image processing due to the physiological radiopharmaceutical uptake in the gastrointestinal tract were excluded from the study.

The patients were informed about the imaging process and possible complications: thereafter, an informed consent form was obtained from each patient. The medications with beta-blockers, calcium channel blockers, and longacting nitrates were discontinued for 48 hours before imaging. Patients were informed concerning they should not drink tea or coffee in the last 24 hours and avoid food and fluid intake for the last 4 hours.

An anamnesis was taken and blood pressure was measured in imaging day. Then, a nuclear medicine physician evaluated the choice of stress test method regarding whether to apply pharmacologically or by effort. A single day (stress-rest) protocol was performed to all patients. The rest imaging was not performed on patients in the absence of any defect or suspicious lesion visually.

The treadmill exercise test was applied to the patients who were planned to undergo stress test by effort. The targeted heart rate (220-age) was calculated according to the Bruce/modified Bruce protocol. Then $9 \mathrm{mCi} \mathrm{Tc}-$ 99m MIBI injection was administered to the patients who reached $85 \%$ of the targeted heart rate. Patients were expected to reach $100 \%$ of the targeted heart rate following injection. The protocol was continued for at least 1 minute for those who failed to reach $100 \%$ of the targeted heart rate.

Adenosine was used in an attempt to establish pharmacological stress if there was no contraindication.
The patients were monitorized and then intravenous adenosine infusion was initiated with the dosage of 140 $\mathrm{mcg} / \mathrm{kg} / \mathrm{m}$. In the third minute of the infusion, $9 \mathrm{mCi}$ MIBI injection was administered. Thereafter, the adenosine infusion was continued for three minutes and the test was terminated. Imaging was performed on all stress test applied patients 30-45 minutes after Tc-99m MIBI injection.

The SPECT images were obtained by using GATED, Mediso AnyScan dual-head gamma camera (Mediso AnyScan, Hungary) with $64 \times 64$ matrix, $140-\mathrm{keV}$ peak, $20 \%$ energy window, step\&shot technique ( 25 seconds), high-resolution parallel-hole collimators to acquire $32 \times 40$-s projections along a $180^{\circ}$, non-circular orbit with heads at $90^{\circ}$ from another. Raw images were filtered by using a Butterworth back projection.

After 3 hours of radiopharmaceutical injection during the stress test, $23 \mathrm{mCi}$ Tc-99m MIBI injection was performed in resting patients. Then, the rest MPS images of the patients were obtained with the same imaging protocol 45-60 minutes after injection.

\section{Imaging Analysis and Evaluation of Biochemical Parameters}

Imaging analysis was performed by an experienced nuclear medicine physician. To determine the ejection fraction, Cedar's Sinai Quantitative GATED SPECT and, for ischemia scores, Cedar's Sinai Quantitative Perfusion SPECT package program were used. Ejection fraction was determined with GATED images. In ischemia scoring, left ventricle myocardium was separated into 17 segments and each was scored from 0 to 4 (Table 1). SSS, SRS, SDS, stress TPD, and rest TPD measurements were obtained by using the program. However, the percentage of total perfusion defect (difference TPD) between rest and perfusion images was calculated manually.

The high SRS and rest TPD values were evaluated as a fixed defect (infarct) because of demonstrating the presence of a defect in resting myocardium. On the other 
hand, high SDS and difference TPD values were defined as a reversible defect to express the recovery in rest images, which was found previously in stress images. SSS $>3$ and SDS $>2$ values were considered as abnormal ${ }^{(3,9)}$.

The cut off values were set as: fasting blood glucose $125 \mathrm{mg} / \mathrm{dL}$, total cholesterol and triglyceride $200 \mathrm{mg} / \mathrm{dL}$, HDL 40 mg/dL, LDL 130 mg/dL ${ }^{(10)}$.

\section{Statistical Analysis}

The acquired data were evaluated by using IBM SPSS 22 (Armonk, NY) package program. The mean values and range were used for variables. Biochemical parameters, ejection fraction (EF), gender in all patients, patients with coronary artery disease (CAD) and those with no diagnosis of CAD; the results of left ventricular myocardium scores and perfusion defects were compared. The Student's t-test was used in pairwise comparisons. The binary logistic regression test was used to figure out the parameters affecting abnormal SSS and SDS values. A $p$ value of $<0.05$ was considered as statistically significant.

\section{Results}

The mean age of 274 patients (125 female, 149 male) was $62 \pm 11$ years. During imaging, 99 patients (36\%) had a diagnosis of CAD confirmed by coronary angiography. Sixty-four (65\%) of patients had a history of stent, 22 (22\%) had a history of by-pass, and five (5\%) had a history of bypass + stent. Eight $(8 \%)$ patients were on medical follow up. Besides, 72 (26\%) patients had diabetes mellitus, 21 $(8 \%)$ of whom were under insulin treatment.

\section{All Patients}

Abnormal SSS and SDS values were observed in $196(72 \%)$ and 172 (63\%) patients respectively. SDS

Table 1. Five-point scale

\begin{tabular}{|l|l|}
\hline Point & Meaning \\
\hline 0 & Normal \\
\hline 1 & Slightly reduction uptake \\
\hline 2 & Moderate reduction uptake \\
\hline 3 & Severe reduction uptake \\
\hline 4 & Absent of uptake \\
\hline
\end{tabular}

value was severely high $(\geq 7)$ in 60 patients. Meanwhile, in $36(13 \%)$ patients, difference TDP was $\geq 10 \%$. There were significant differences among fasting blood glucose, HDL, EF, the presence of CAD, gender, and some MPS scores. These outcomes were presented in Table 2. In patients with fasting blood glucose above $125 \mathrm{mg} / \mathrm{dL}$, reversible defect was more frequent. When there were more fixed defects in patients with HDL value of $<40 \mathrm{mg} / \mathrm{dL}$, reversible defects were more common in the individuals with $\geq 40 \mathrm{mg} / \mathrm{dL}$ HDL levels. The patients with $\mathrm{EF}<50 \%$ and $\mathrm{CAD}+$, the fixed defect percentage was significantly higher. While more fixed defects were observed in males, reversible defects were more common in females. However, there was no statistically significant difference among total cholesterol, triglyceride, LDL levels and global scores, and TPD values. $\mathrm{EF}$ value (Wald $=6.063, \mathrm{HR}=1.037$ (95\% Cl=1.007-1.067), $\mathrm{p}=0.014)$ and male gender (Wald $=8.592, \quad H R=2.257 \quad(95 \% \quad \mathrm{Cl}=1.310-3.890)$, $\mathrm{p}=0.003$ ) were found to be independent factors to predict abnormal SSS. Triglyceride level (Wald $=5.102$, $\mathrm{HR}=1.004(95 \% \mathrm{Cl}=1.001-1.007), \mathrm{p}=0.024)$ and female gender $\quad($ Wald $=16.981, \quad \mathrm{HR}=3.021 \quad(95 \% \quad \mathrm{Cl}=1.786$ 5.112), $\mathrm{p}<0.001)$ were determined as independent predictors to detect abnormal SDS.

\section{CAD+ Group}

There were abnormal SSS and SDS values in 78 $(79 \%)$ and $66(67 \%)$ respectively. SDS value was $\geq 7$ in $24(24 \%)$ patients. Therewithal, in $15(15 \%)$ patients, the difference TPD was $\geq 10 \%$. Table 3 presents the results during MPS imaging regarding $\mathrm{CAD}+$ patients. $\mathrm{CAD}+$ and triglyceride $>200 \mathrm{mg} / \mathrm{dL}$ patients had more fixed defects, when compared to triglyceride $\leq 200 \mathrm{mg} / \mathrm{dL}$ ones. Nonetheless, the frequency of fixed defects was higher in patients with $\mathrm{EF}<50$ either. In the $\mathrm{CAD}+$ group, reversible defects were more common in females rather than males. Although more fixed defects were observed in males, this difference was not statistically significant. In CAD+ patients, there was no difference among fasting blood glucose, total cholesterol, LDL, HDL levels and MPS 
scores or TPD percentages. Female gender was found to be an independent predictor for the detection of abnormal $\mathrm{SDS}$ in this group (Wald $=4.390, \mathrm{HR}=2.778 \quad(95 \%$ $\mathrm{Cl}=1.068-7.224), \mathrm{p}=0.036$ ).

\section{Suspicious CAD+ Group}

In this group, SSS in $118(67 \%)$ and SDS in $106(61 \%)$ patients were abnormal. In $36(21 \%)$ patients, SDS values were $\geq 7$ and 21 (12\%) patients had difference TPD values greater than or equal to $10 \%$. In Table 4 , the results of the non-CAD diagnosed patients during MPS images are presented. There were more observed reversible defects in total cholesterol $>200 \mathrm{mg} / \mathrm{dL}$ subgroup in this cohort. In patients with $\mathrm{HDL}<40 \mathrm{mg} / \mathrm{dL}$ and $\mathrm{EF}<50$, the fixed defect rate was higher while the reversible defects were more common in patients with $\mathrm{HDL} \geq 40 \mathrm{mg} / \mathrm{dL}$. In the non-CAD (suspected CAD) group, male patients had less fixed defects while more reversible defects were observed in females. However, there was no significant difference in comparisons among fasting blood glucose, triglyceride, LDL levels and MPS scores, TPD percentages, in this group.

Table 2. Global scores of all patients according to fasting blood glucose, lipid profile, EF, CAD, and gender

\begin{tabular}{|c|c|c|c|c|c|c|c|}
\hline & $n$ & sss & SRS & SDS & $\begin{array}{l}\text { Stress TPD } \\
(\%)\end{array}$ & $\begin{array}{l}\text { Rest TPD } \\
(\%)\end{array}$ & $\begin{array}{l}\text { Difference } \\
\text { TPD (\%) }\end{array}$ \\
\hline Total & 274 & $7.8 \pm 7.1$ & $3.7 \pm 6.2$ & $4.2 \pm 3.2$ & $8.9 \pm 9.2$ & $3.7 \pm 7.9$ & $5.2 \pm 3.7$ \\
\hline $\begin{array}{l}\text { Glucose } \\
\leq 125 \mathrm{mg} / \mathrm{dL} \\
>125 \mathrm{mg} / \mathrm{dL} \\
\mathrm{p} \text { value }\end{array}$ & $\begin{array}{l}192 \\
82\end{array}$ & $\begin{array}{l}7.6 \pm 7.0 \\
8.5 \pm 7.0 \\
0.307\end{array}$ & $\begin{array}{l}3.7 \pm 6.2 \\
3.7 \pm 6.5 \\
\mathbf{0 . 9 6 3}\end{array}$ & $\begin{array}{l}3.9 \pm 3.2 \\
4.8 \pm 3.2 \\
0.034^{*}\end{array}$ & $\begin{array}{l}8.6 \pm 9.4 \\
9.6 \pm 8.9 \\
0.426\end{array}$ & $\begin{array}{l}3.7 \pm 7.7 \\
3.8 \pm 8.5 \\
0.917\end{array}$ & $\begin{array}{l}4.9 \pm 3.8 \\
5.8 \pm 3.7 \\
0.082\end{array}$ \\
\hline $\begin{array}{l}\text { Total cholesterol } \\
\leq 200 \mathrm{mg} / \mathrm{dL} \\
>200 \mathrm{mg} / \mathrm{dL} \\
\mathrm{p} \text { value }\end{array}$ & $\begin{array}{l}135 \\
139\end{array}$ & $\begin{array}{l}8.3 \pm 7.8 \\
7.4 \pm 6.2 \\
0.324\end{array}$ & $\begin{array}{l}4.4 \pm 6.9 \\
3.1 \pm 5.5 \\
0.094\end{array}$ & $\begin{array}{l}3.9 \pm 3.2 \\
4.4 \pm 3.1 \\
0.260\end{array}$ & $\begin{array}{l}9.6+10.1 \\
8.2 \pm 8.2 \\
\mathbf{0 . 2 1 5}\end{array}$ & $\begin{array}{l}4.4 \pm 8.7 \\
3.1 \pm 7.1 \\
0.168\end{array}$ & $\begin{array}{l}5.2 \pm 4.0 \\
5.1 \pm 3.6 \\
0.902\end{array}$ \\
\hline $\begin{array}{l}\text { Triglyceride } \\
\leq 200 \mathrm{mg} / \mathrm{dL} \\
>200 \mathrm{mg} / \mathrm{dL} \\
\mathrm{p} \text { value }\end{array}$ & $\begin{array}{l}218 \\
56\end{array}$ & $\begin{array}{l}7.6 \pm 6.5 \\
8.8 \pm 8.9 \\
0.368\end{array}$ & $\begin{array}{l}3.5 \pm 5.8 \\
4.7 \pm 7.6 \\
0.275\end{array}$ & $\begin{array}{l}4.2 \pm 3.1 \\
4.1 \pm 3.5 \\
0.881\end{array}$ & $\begin{array}{l}8.6 \pm 8.5 \\
10.3 \pm 11.7 \\
\mathbf{0 . 2 9 5}\end{array}$ & $\begin{array}{l}3.4 \pm 7.3 \\
5.2 \pm 9.9 \\
0.204\end{array}$ & $\begin{array}{l}5.2 \pm 3.7 \\
5.1 \pm 4.1 \\
\mathbf{0 . 9 3 1}\end{array}$ \\
\hline $\begin{array}{l}\mathrm{HDL} \\
<40 \mathrm{mg} / \mathrm{dL} \\
\geq 40 \mathrm{mg} / \mathrm{dL} \\
p \text { value }\end{array}$ & $\begin{array}{l}92 \\
182\end{array}$ & $\begin{array}{l}8.8 \pm 7.8 \\
7.4 \pm 6.6 \\
0.129\end{array}$ & $\begin{array}{l}5.2 \pm 7.2 \\
3.0 \pm 5.6 \\
0.010^{*}\end{array}$ & $\begin{array}{l}3.6 \pm 2.8 \\
4.4 \pm 3.3 \\
0.047^{*}\end{array}$ & $\begin{array}{l}10.4 \pm 10.4 \\
8.2 \pm 8.5 \\
\mathbf{0 . 0 7 9}\end{array}$ & $\begin{array}{l}5.4 \pm 8.8 \\
2.9 \pm 7.4 \\
0.024^{*}\end{array}$ & $\begin{array}{l}5.0 \pm 3.3 \\
5.2 \pm 4.0 \\
\mathbf{0 . 1 9 8}\end{array}$ \\
\hline $\begin{array}{l}\text { LDL } \\
\leq 130 \mathrm{mg} / \mathrm{dL} \\
>130 \mathrm{mg} / \mathrm{dL} \\
p \text { value }\end{array}$ & $\begin{array}{l}146 \\
128\end{array}$ & $\begin{array}{l}8.0 \pm 7.4 \\
7.6 \pm 6.6 \\
0.614\end{array}$ & $\begin{array}{l}4.0 \pm 6.4 \\
3.4 \pm 6.1 \\
0.394\end{array}$ & $\begin{array}{l}4.0 \pm 3.3 \\
4.3 \pm 3.0 \\
0.561\end{array}$ & $\begin{array}{l}9.3 \pm 9.6 \\
8.5 \pm 8.7 \\
0.473\end{array}$ & $\begin{array}{l}4.0 \pm 8.2 \\
3.4 \pm 7.6 \\
0.504\end{array}$ & $\begin{array}{l}5.2 \pm 4.0 \\
5.1 \pm 3.5 \\
0.724\end{array}$ \\
\hline $\begin{array}{l}\text { EF } \\
<50 \% \\
\geq 50 \% \\
p \text { value }\end{array}$ & $\begin{array}{l}42 \\
232\end{array}$ & $\begin{array}{l}15.6 \pm 10.4 \\
6.4 \pm 5.1 \\
<0.001^{*}\end{array}$ & $\begin{array}{l}11.9 \pm 9.9 \\
2.2 \pm 3.7 \\
<0.001^{*}\end{array}$ & $\begin{array}{l}3.8 \pm 3.1 \\
4.2 \pm 3.2 \\
0.457\end{array}$ & $\begin{array}{l}19.5 \pm 14.1 \\
7.0 \pm 6.4 \\
<0.001^{*}\end{array}$ & $\begin{array}{l}14.2 \pm 13.4 \\
1.9 \pm 4.4 \\
<0.001^{*}\end{array}$ & $\begin{array}{l}5.4 \pm 3.8 \\
5.1 \pm 3.8 \\
0.719\end{array}$ \\
\hline $\begin{array}{l}\text { CAD } \\
\text { Positive } \\
\text { Negative } \\
\text { p value }\end{array}$ & $\begin{array}{l}99 \\
175\end{array}$ & $\begin{array}{l}10.6 \pm 9.1 \\
6.3 \pm 5.0 \\
<0.001^{*}\end{array}$ & $\begin{array}{l}6.2 \pm 8.2 \\
2.3 \pm 4.2 \\
<0.001^{*}\end{array}$ & $\begin{array}{l}4.4 \pm 3.6 \\
4.0 \pm 3.0 \\
0.333\end{array}$ & $\begin{array}{l}12.6 \pm 12.1 \\
6.8 \pm 6.3 \\
<0.001^{*}\end{array}$ & $\begin{array}{l}6.9 \pm 10.8 \\
2.0 \pm 4.9 \\
<0.001^{*}\end{array}$ & $\begin{array}{l}5.7 \pm 4.2 \\
4.9 \pm 3.4 \\
0.078\end{array}$ \\
\hline $\begin{array}{l}\text { Gender } \\
\text { Female } \\
\text { Male } \\
\text { p value }\end{array}$ & $\begin{array}{l}125 \\
149\end{array}$ & $\begin{array}{l}7.9 \pm 5.8 \\
7.7 \pm 8.0 \\
0.847\end{array}$ & $\begin{array}{l}2.4 \pm 4.1 \\
4.8 \pm 7.4 \\
0.001^{*}\end{array}$ & $\begin{array}{l}5.5 \pm 3.6 \\
3.0 \pm 2.3 \\
<0.001^{*}\end{array}$ & $\begin{array}{l}8.7 \pm 7.4 \\
9.0 \pm 10.5 \\
\mathbf{0 . 7 7 5}\end{array}$ & $\begin{array}{l}2.3 \pm 5.0 \\
4.9 \pm 9.6 \\
0.005^{\star}\end{array}$ & $\begin{array}{l}6.4 \pm 4.2 \\
4.1 \pm 3.0 \\
<0.001^{*}\end{array}$ \\
\hline
\end{tabular}

n: Number of the patients, SSS=Summed stress score, SRS: Summed rest score, SDS: Summed difference score, TPD: Total perfusion defect, HDL: Highdensity lipoprotein, LDL: Low-density lipoprotein, CAD: Coronary artery disease, EF: Ejection fraction 
Table 3. CAD positive patients global scoring

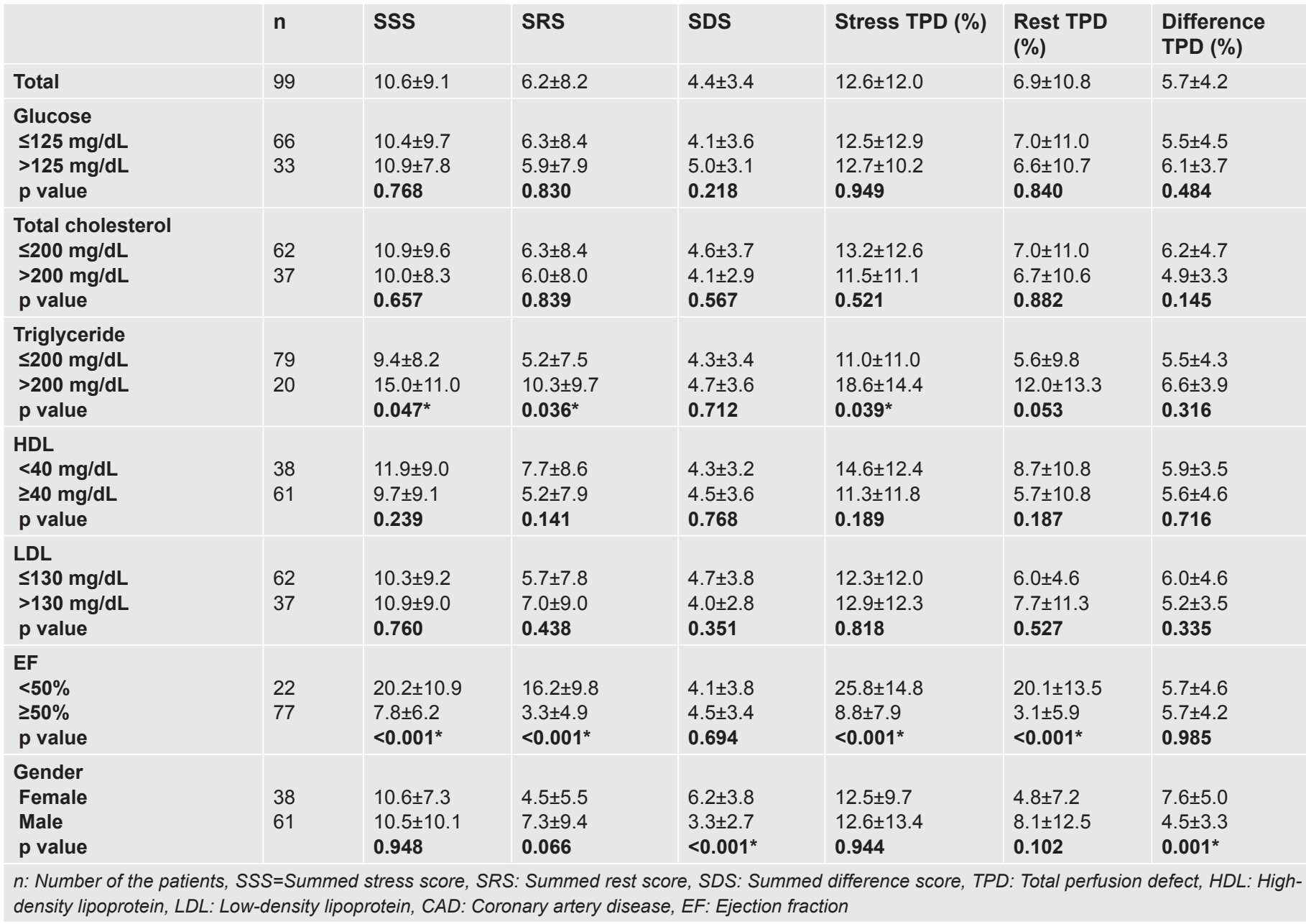

\section{Discussion}

In our study, abnormal SSS and SDS were observed in 196 (72\%) and 172 (63\%) patients, respectively. Higher global scores were observed in patients with elevated HDL and fasting blood glucose levels. Furthermore, $\mathrm{CAD}+$ patients with high triglyceride and CAD-patients with high total cholesterol and HDL levels were also found to be associated with high global scores, either. Independently from the fasting blood glucose and lipid profile, the presence of more fixed defects was observed in patients with impaired $\mathrm{EF}(<50 \%)$ and male gender. On the other hand, reversible defect frequency was higher in the female gender.
Diabetes is a well-known risk factor for $\mathrm{CAD}^{(11,12)}$. Beyond that, more cardiovascular event occurrence is reported with elevating blood glucose levels ${ }^{(13)}$. Furthermore, Ghatak et al. ${ }^{(14)}$ documented that diabetic patients had higher SSS when compared to non-diabetic patients and consequently development of cardiac event was more common in this group. On the contrary, there was no significant difference between diabetic and non-diabetic populations in terms of SSS in our study. However, SDS was observed to be statistically higher in patients with fasting blood glucose $>125 \mathrm{mg} /$ $\mathrm{dL}$. This circumstance may be interpreted in favor of that the diabetic patients have more reversible defects. 
Table 4. CAD negative patients global scoring

\begin{tabular}{|c|c|c|c|c|c|c|c|}
\hline & $\mathbf{n}$ & sss & SRS & SDS & Stress TPD (\%) & Rest TPD (\%) & Difference TPD (\%) \\
\hline Total & 175 & $6.3 \pm 5.0$ & $2.3 \pm 4.2$ & $4.0 \pm 3.0$ & $6.8 \pm 6.3$ & $2.0 \pm 4.9$ & $4.9 \pm 3.4$ \\
\hline $\begin{array}{l}\text { Glucose } \\
\leq 125 \mathrm{mg} / \mathrm{dL} \\
>125 \mathrm{mg} / \mathrm{dL} \\
p \text { value }\end{array}$ & $\begin{array}{l}129 \\
46\end{array}$ & $\begin{array}{l}6.3 \pm 5.2 \\
6.3 \pm 4.6 \\
0.957\end{array}$ & $\begin{array}{l}2.5 \pm 4.4 \\
1.8 \pm 3.8 \\
0.358\end{array}$ & $\begin{array}{l}3.8 \pm 2.9 \\
4.5 \pm 3.2 \\
0.178\end{array}$ & $\begin{array}{l}6.8 \pm 6.6 \\
6.9 \pm 5.4 \\
0.992\end{array}$ & $\begin{array}{l}2.2 \pm 5.1 \\
1.4 \pm 4.2 \\
0.328\end{array}$ & $\begin{array}{l}4.6 \pm 3.4 \\
5.5 \pm 3.6 \\
0.159\end{array}$ \\
\hline $\begin{array}{l}\text { Total cholesterol } \\
\leq 200 \mathrm{mg} / \mathrm{dL} \\
>200 \mathrm{mg} / \mathrm{dL} \\
\mathrm{p} \text { value }\end{array}$ & $\begin{array}{l}102 \\
73\end{array}$ & $\begin{array}{l}6.0 \pm 5.1 \\
6.5 \pm 5.0 \\
0.429\end{array}$ & $\begin{array}{l}2.7 \pm 4.7 \\
2.0 \pm 3.8 \\
0.323\end{array}$ & $\begin{array}{l}3.4 \pm 2.7 \\
4.4 \pm 3.2 \\
0.024^{*}\end{array}$ & $\begin{array}{l}6.6 \pm 6.1 \\
7.0 \pm 6.4 \\
\mathbf{0 . 6 5 8}\end{array}$ & $\begin{array}{l}2.2 \pm 5.2 \\
1.8 \pm 4.7 \\
0.560\end{array}$ & $\begin{array}{l}4.4 \pm 3.1 \\
5.2 \pm 3.6 \\
0.100\end{array}$ \\
\hline $\begin{array}{l}\text { Triglyceride } \\
\leq 200 \mathrm{mg} / \mathrm{dL} \\
>200 \mathrm{mg} / \mathrm{dL} \\
\mathrm{p} \text { value }\end{array}$ & $\begin{array}{l}139 \\
36\end{array}$ & $\begin{array}{l}6.6 \pm 5.0 \\
5.3 \pm 5.1 \\
0.187\end{array}$ & $\begin{array}{l}2.5 \pm 4.4 \\
1.5 \pm 3.5 \\
\mathbf{0 . 2 2 1}\end{array}$ & $\begin{array}{l}4.1 \pm 2.9 \\
3.8 \pm 3.4 \\
0.613\end{array}$ & $\begin{array}{l}7.1 \pm 6.2 \\
5.7 \pm 6.6 \\
\mathbf{0 . 2 3 4}\end{array}$ & $\begin{array}{l}2.1 \pm 5.1 \\
1.4 \pm 4.0 \\
\mathbf{0 . 4 2 0}\end{array}$ & $\begin{array}{l}5.0 \pm 3.3 \\
4.3 \pm 4.0 \\
\mathbf{0 . 3 0 2}\end{array}$ \\
\hline $\begin{array}{l}\mathrm{HDL} \\
<40 \mathrm{mg} / \mathrm{dL} \\
\geq 40 \mathrm{mg} / \mathrm{dL} \\
\mathrm{p} \text { value }\end{array}$ & $\begin{array}{l}54 \\
121\end{array}$ & $\begin{array}{l}6.6 \pm 6.0 \\
6.2 \pm 4.6 \\
0.598\end{array}$ & $\begin{array}{l}3.4 \pm 5.4 \\
1.8 \pm 3.5 \\
0.022^{*}\end{array}$ & $\begin{array}{l}3.2 \pm 2.4 \\
4.4 \pm 3.2 \\
0.009 *\end{array}$ & $\begin{array}{l}7.4 \pm 7.6 \\
6.6 \pm 5.7 \\
0.414\end{array}$ & $\begin{array}{l}3.0 \pm 6.0 \\
1.5 \pm 4.2 \\
\mathbf{0 . 1 0 7}\end{array}$ & $\begin{array}{l}4.4 \pm 3.0 \\
5.1 \pm 3.6 \\
0.263\end{array}$ \\
\hline $\begin{array}{l}\text { LDL } \\
\leq 130 \mathrm{mg} / \mathrm{dL} \\
>130 \mathrm{mg} / \mathrm{dL} \\
p \text { value }\end{array}$ & $\begin{array}{l}84 \\
91\end{array}$ & $\begin{array}{l}6.3 \pm 5.3 \\
6.3 \pm 4.8 \\
0.916\end{array}$ & $\begin{array}{l}2.8 \pm 4.8 \\
1.9 \pm 3.6 \\
0.167\end{array}$ & $\begin{array}{l}3.6 \pm 2.9 \\
4.4 \pm 3.1 \\
0.084\end{array}$ & $\begin{array}{l}7.0 \pm 6.6 \\
6.7 \pm 6.0 \\
0.712\end{array}$ & $\begin{array}{l}2.4 \pm 5.3 \\
1.6 \pm 4.5 \\
0.325\end{array}$ & $\begin{array}{l}4.7 \pm 3.4 \\
5.0 \pm 3.5 \\
0.471\end{array}$ \\
\hline $\begin{array}{l}\text { EF } \\
<50 \% \\
\geq 50 \% \\
p \text { value }\end{array}$ & $\begin{array}{l}20 \\
155\end{array}$ & $\begin{array}{l}10.6 \pm 7.2 \\
5.7 \pm 4.4 \\
0.008^{*}\end{array}$ & $\begin{array}{l}7.3 \pm 8.0 \\
1.7 \pm 2.9 \\
0.006^{*}\end{array}$ & $\begin{array}{l}3.5 \pm 2.0 \\
4.1 \pm 3.1 \\
0.237\end{array}$ & $\begin{array}{l}12.6 \pm 9.6 \\
6.1 \pm 5.4 \\
0.007^{*}\end{array}$ & $\begin{array}{l}7.6 \pm 10.0 \\
1.3 \pm 3.2 \\
\mathbf{0 . 0 1 1}^{*}\end{array}$ & $\begin{array}{l}5.0 \pm 2.8 \\
4.9 \pm 3.5 \\
0.851\end{array}$ \\
\hline $\begin{array}{l}\text { Gender } \\
\text { Female } \\
\text { Male } \\
\text { p value }\end{array}$ & $\begin{array}{l}87 \\
88\end{array}$ & $\begin{array}{l}6.7 \pm 4.6 \\
5.9 \pm 5.4 \\
0.246\end{array}$ & $\begin{array}{l}1.5 \pm 3.0 \\
3.1 \pm 5.1 \\
0.018^{*}\end{array}$ & $\begin{array}{l}5.2 \pm 3.4 \\
2.8 \pm 2.0 \\
<0.001^{*}\end{array}$ & $\begin{array}{l}7.1 \pm 5.6 \\
6.6 \pm 7.0 \\
0.568\end{array}$ & $\begin{array}{l}1.3 \pm 3.2 \\
2.7 \pm 6.1 \\
0.051\end{array}$ & $\begin{array}{l}5.9 \pm 3.8 \\
3.9 \pm 2.7 \\
<0.001^{*}\end{array}$ \\
\hline
\end{tabular}

$n$ : Number of the patients, SSS=Summed stress score, SRS: Summed rest score, SDS: Summed difference score, TPD: Total perfusion defect, HDL: Highdensity lipoprotein, LDL: Low-density lipoprotein, CAD: Coronary artery disease, EF: Ejection fraction

In a study including the patients with $\mathrm{SSS}>4$, diabetic patients had $\mathrm{SSS}=13.9 \pm 11.3, \mathrm{SDS}=7.4 \pm 1.2^{(15)}$. However, our study included all diabetic patients regardless of SSS; therefore, SSS and SDS were lower as expected.

Several articles in the literature have specified SSS, SDS, hyperlipidemia, serum creatinine level, gender, and EF value as independent predictive factors for the detection of cardiac event development ${ }^{(16,17)}$. Similarly, impaired $\mathrm{EF}$ and male gender were found to be in correlation with elevated SSS while triglyceride levels and female gender were in correlation with SDS. Considering that elevated SSS and SDS are associated with increased cardiac events, our results are compatible with the current literature.
Another study calculated SSS, SRS, and SDS values as $13.3 \pm 6.0,5.0 \pm 4.1$, and $8.3 \pm 4.6$, respectively, in patients with known $\mathrm{CAD}$ and not receiving statin therapy despite dyslipidemia ${ }^{(18)}$. The fact that the patients receiving statin therapy were excluded from the study suggests that only the patients with the diagnosis of new-onset CAD were included in the study. Although our results are similar to this study, we measured higher SRS and lower SDS. These differences indicate that we observed more fixed defects. The underlying reason for this circumstance is the inclusion of early diagnosed CAD patients together with known cases of longstanding CAD in our study. 
White et al. ${ }^{(19)}$ reported that although elevated LDL and triglyceride levels were in correlation with CAD, the association between decreased HDL levels and CAD was suspicious. In accordance with the literature, in CAD + patients, elevated triglyceride levels and fix defect existence were found to be related in our study. Nevertheless, when all patients and CAD-group were considered, we observed that decreased HDL levels were found to be in association with the presence of fixed defects. According to the results of our study, low HDL is thought to be associated with CAD.

Zakavi et al. ${ }^{(20)}$ have not detected any difference between ischemia and non-ischemia groups in patients without the diagnosis of CAD in terms of total cholesterol, triglyceride, HDL and LDL values. Compatible with this study, our results did not reveal any difference among high triglyceride, LDL levels, and MPS scores. On the other hand, the relationships between high total cholesterol and reversible defect and between decreased HDL level and fixed defect in CAD-group were statistically significant.

In both gender, cardiovascular disease is more common in men at similar ages. This is thought to be due to the protective effect of sex hormones. On the other hand, risk factors that may cause cardiovascular disease are more common in woman ${ }^{(21)}$. In a study conducted with the European data of WHO, the mortality in females due to CAD was found to be higher ${ }^{(22)}$. Another study observed more rest perfusion defects in females ${ }^{(23)}$. In our study, although the perfusion defects were found to be approximately equal in both genders, perfusion defects in males tended to be fixed defect while reversible defects were more common in females.

Our study has several particularly inherited limitations due to its retrospective design. In addition, our patient group is generally composed of low-to-medium-risk groups because of directing high-risk patients directly to the interventional processes without MPS imaging.

According to the protocol of our clinic, stress imaging is performed initially. Then, if there are suspicious defects in the images, the resting imaging is carried out.
Otherwise, the second protocol is cancelled. Therefore, low-probability individuals from our patient group were also excluded involuntarily. For this reason, our study remains inadequate to represent all $\mathrm{CAD}+$ or suspected $\mathrm{CAD}+$ patient population.

\section{Conclusion}

Herein with this study, EF and gender were determined as independent predictors for SSS while triglyceride levels and gender were for SDS in the same manner. Beyond that, our study demonstrates that fasting blood glucose, lipid profile, gender, and EF values may aid to predict MPS global scores and total perfusion defects.

\section{Ethics}

Ethics Committee Approval: The approval of Local Ethical Comittee with a decision number 247, date 30/05/2019 was obtained.

Informed Consent: Informed consent form was obtained from each patient.

Peer-review: Externally and internally peer-reviewed.

Financial Disclosure: The author stated that this study received no financial support.

\section{References}

1. Berman DS, Abidov A, Kang X, Hayes SW, Friedman JD, Sciammarella $\mathrm{MG}$, et al. Prognostic validation of a 17-segment score derived from a 20-segment score for myocardial perfusion spect interpretation. Journal of Nuclear Cardiology 2004;11:414-23.

2. Germano G, Kavanagh PB, Slomka PJ, Van Kriekinge SD, Pollard G, Berman DS. Quantitation in gated perfusion SPECT imaging: The CedarsSinai approach. Journal of Nuclear Cardiology 2007;14:433-54.

3. Leslie WD, Tully SA, Yogendran MS, Ward LM, Nour KA, Metge CJ. Prognostic value of automated quantification of $99 \mathrm{mTc}-\mathrm{sestamibi}$ myocardial perfusion imaging. J Nucl Med 2005;46:204-11.

4. Montalescot G, Sechtem U, Achenbach S, et al. 2013 ESC guidelines on the management of stable coronary artery disease: the Task Force on the management of stable coronary artery disease of the European Society of Cardiology. Eur Heart J 2013;34:2949-3003.

5. Hachamovitch R, Hayes SW, Friedman JD, Cohen I, Berman DS Comparison of the short-term survival benefit associated with revascularization compared with medical therapy in patients with no prior coronary artery disease undergoing stress myocardial perfusion single photon emission computed tomography. Circulation 2003;107:2900-7. 
6. Mozaffarian D, Benjamin EJ, Go AS, et al. Heart Disease and Stroke Statistics-2016 Update: A Report From the American Heart Association. Circulation 2016;133:e38-360.

7. Srinivasan M, Herrero P, McGill JB, et al. The effects of plasma insulin and glucose on myocardial blood flow in patients with type 1 diabetes mellitus. J Am Coll Cardiol 2005;46:42-8.

8. Mostaza JM, Gomez MV, Gallardo F, et al. Cholesterol reduction improves myocardial perfusion abnormalities in patients with coronary artery disease and average cholesterol levels. J Am Coll Cardiol 2000;35:76-82.

9. Leslie WD, Tully SA, Yogendran MS, Ward LM, Nour KA, Metge CJ. Automated quantification of $99 \mathrm{mTc}$ sestamibi myocardial perfusion compared with visual analysis. Nucl Med Commun 2004;25:833-8.

10. Onat A, Büyüköztürk K, Sansoy V, Avcı GŞ, Çam N, Akgün G, et al. Türk Kardiyoloji Derneği Koroner Kalp Hastalığı Korunma ve Tedavi Kilavuzu (Available from: https://www.tkd.org.tr/kilavuz/k11/4e423. htm?wbnum $=1604$

11. Nasr G, Sliem H. Silent myocardial ischemia in prediabetics in relation to insulin resistance. J Cardiovasc Dis Res 2010;1:116-21.

12. Wu YT, Chien CL, Wang SY, Yang WS, Wu YW. Gender differences in myocardial perfusion defect in asymptomatic postmenopausal women and men with and without diabetes mellitus. J Womens Health (Larchmt) 2013;22:439-44.

13. Oto A. Diabetes and coronary artery disease: Scary duo of the developing world. EJCM 2013;01:45-49.

14. Ghatak A, Padala S, Katten DM, Polk DM, Heller GV. Risk stratification among diabetic patients undergoing stress myocardial perfusion imaging. $\mathrm{J}$ Nucl Cardiol 2013;20:529-38.

15. Prior JO, Monbaron D, Koehli M, Calcagni ML, Ruiz J, Bischof Delaloye A. Prevalence of symptomatic and silent stress-induced perfusion defects in diabetic patients with suspected coronary artery disease referred for myocardial perfusion scintigraphy. Eur $\mathrm{J}$ Nucl Med Mol Imaging 2005;32:60-9.

16. Romero-Farina G, Candell-Riera J, Aguade-Bruix S, Garcia Dorado D. A novel clinical risk prediction model for myocardial infarction, coronary revascularization, and cardiac death according to clinical, exercise, and gated SPECT variables (VH-RS). Eur Heart J Cardiovasc Imaging 2019;3: pii: jez078.

17. Gimelli A, Rossi G, Landi P, et al. Stress/Rest Myocardial Perfusion Abnormalities by Gated SPECT: Still the Best Predictor of Cardiac Events in Stable Ischemic Heart Disease. J Nucl Med 2009;50:546-53.

18. Schwartz RG, Pearson TA, Kalaria VG, et al. Prospective serial evaluation of myocardial perfusion and lipids during the first six months of pravastatin therapy: coronary artery disease regression single photon emission computed tomography monitoring trial. J Am Coll Cardiol 2003;42:600-10.

19. White J, Swerdlow DI, Preiss D, et al. Association of Lipid Fractions With Risks for Coronary Artery Disease and DiabetesLipid Fractions and Risks of Coronary Artery Disease and DiabetesLipid Fractions and Risks of Coronary Artery Disease and Diabetes. JAMA Cardiol 2016;1:692-9.

20. Zakavi SR, Taherpour M, Moossavi Z, Sadeghi R, Kakhki VD, Rokni H. Clinical value and severity of myocardial perfusion defects in asymptomatic diabetic patients with negative or weakly positive exercise treadmill test. Asia Ocean J Nucl Med Biol 2013;1:14-9.

21. Wakabayashi I. Gender differences in cardiovascular risk factors in patients with coronary artery disease and those with type 2 diabetes. Journal of thoracic disease 2017;9:E503-6.

22. Appelman Y, van Rijn BB, ten Haaf ME, Boersma E, Peters SAE. Sex differences in cardiovascular risk factors and disease prevention. Atherosclerosis. 2015;241:211-8.

23. Byrne C, Kuhl JT, Zacho M, et al. Sex- and age-related differences of myocardial perfusion at rest assessed with multidetector computed tomography. J Cardiovasc Comput Tomogr 2013;7:94-101. 